\title{
BMJ Open Perspectives of time: a qualitative study of the experiences of parents of critically ill newborns in the neonatal nursery in North Queensland interviewed several years after the admission
}

\author{
Susan Ireland, ${ }^{1,2}$ Robin A Ray, ${ }^{1}$ Sarah Larkins, ${ }^{\oplus 1}$ Lynn Woodward ${ }^{1}$
}

To cite: Ireland S, Ray RA, Larkins S, et al. Perspectives of time: a qualitative study of the experiences of parents of critically ill newborns in the neonatal nursery in North Queensland interviewed several years after the admission. BMJ Open 2019;9:e026344. doi:10.1136/ bmjopen-2018-026344

- Prepublication history for this paper is available online. To view these files, please visit the journal online (http://dx.doi. org/10.1136/bmjopen-2018026344).

Received 29 August 2018 Revised 30 March 2019 Accepted 1 April 2019

Check for updates

(C) Author(s) (or their employer(s)) 2019. Re-use permitted under CC BY-NC. No commercial re-use. See rights and permissions. Published by BMJ.

1James Cook University College of Medicine and Dentistry,

Townsville, Queensland,

Australia

${ }^{2}$ Townsville Hospital and Health Service, Townsville, Queensland, Australia

Correspondence to

Dr Susan Ireland;

susan.ireland@my.jcu.edu.au

\section{ABSTRACT}

Design A qualitative study informed by grounded theory principles to explore the experiences of parents who had extremely preterm or babies with antenatally diagnosed life-threatening diagnoses who were cared for in a regional tertiary neonatal unit. The study was conducted when the child was old enough to be diagnosed with longterm neurodevelopmental or medical sequelae.

Setting North Queensland is a large area in Eastern Australia of $500000 \mathrm{~km}^{2}$, which is served by one tertiary neonatal unit.

Participants Seventeen families representing 21 extremely preterm babies and one baby with congenital malformations who was not expected to survive prior to delivery (but did) were interviewed using grounded theory principles. Interviews were coded and themes derived.

Results Parents who recollect their neonatal experiences from 3 to 7 years after the baby was cared for in the neonatal intensive care described negative themes of grief and loss, guilt and disempowerment. Positive enhancers of care included parental strengths, religion and culture, family supports and neonatal unit practices. Novel findings included that prior pregnancy loss and infertility formed part of the narrative for parents, and hope was engendered by religion for parents who did not usually have a religious faith.

Conclusions An understanding of both the negative aspects of neonatal care and the positive enhancers is necessary to improve the neonatal experience for parents. Parents are able to contextualise their previous neonatal experiences within both the long-term outcome for the child and their own life history.

\section{INTRODUCTION}

Following delivery, babies born prematurely will remain in hospital until they are able to survive in a home environment. Those babies born at the verge of viability from 22 to 26 weeks' gestation will spend approximately 4 months as inpatients, much of this time in the neonatal intensive care unit (NICU) where the baby's physiological needs can be met by the use of increasingly complex
Strengths and limitations of this study

- The study documents a range of experiences from parents who represent the full diversity of the population treated including Indigenous families who are rarely included in qualitative neonatal studies.

- The study has been done at a time when the babies who received intensive care were old enough that any major difficulties resulting from their perinatal period is known to the families.

- The richness of the data may be compromised if parents were culturally unacquainted with qualitative research and unable to articulate their experiences.

- Parents of babies with poor neurological outcomes who felt negative towards the unit may be under-represented as these parents may be less likely to engage with the study.

technology. ${ }^{12}$ Parents who birth a baby at these gestations will need to cede the care of their infant to the medical and nursing team while trying to maintain parenthood of the baby in this environment until he or she is discharged to home. ${ }^{34}$ Anxiety, depression, stress and trauma are described in parents who have had a baby in a NICU. ${ }^{56}$

To help reduce the suffering of parents, and in turn improve the well-being of their offspring, it is necessary to understand which experiences help parents to adapt to the neonatal environment and which make the stay more difficult. Previous studies suggest that relinquishing the parental role and feelings of inadequacy ${ }^{5-11}$ are some of the most stressful experiences of parents of neonates in NICU. Attachment to the child can be difficult ${ }^{81012}$ with possible long-term consequences of poorer cognition, language and social and emotional outcomes. ${ }^{5}$ Other negative experiences include difficulty inherent in juggling roles away from the 
hospital and leaving the baby. ${ }^{8}{ }^{13}$ Resentment towards nursing staff for being able to spend more time with the baby has been found. ${ }^{14}$ By contrast, positive experiences include a welcoming attitude of the hospital staff, ${ }^{13} 1516$ the ability of the parent to help their baby ${ }^{17}$ and good family support. ${ }^{13}$ Nearly all of these studies investigate the parental experiences while the baby is still in the neonatal unit, or in the first year of life. These findings are verified by healthcare providers who care for neonates in intensive care with personal experience of extremely preterm or medically vulnerable babies. ${ }^{18} 19$ This group of clinicians describe the need for hope, honesty in delivering prognosis, compassion and facilitating connectedness as important. ${ }^{18}$ The lack of control that they experienced during their infants' admission was the most negative feature described.

Little is known about how parents reflect on their NICU experience in the context of the baby's longterm outcome as the implications for both the child and family become evident. With time, early distress related to the early birth may have resolved, replaced with the stressors inherent in caring for the child or sacrifices by the family. ${ }^{4}$ These may affect whether parents feel that the difficulties of NICU care were worthwhile or in fact how they are recalled. This paper explores the experiences of the NICU from the perspective of parents who had babies admitted from 2 years to 7 years prior to the study to allow some contextualisation of their experience over time and inform staff who care for future parents who may be unaware of the adaptation of families.

\section{METHODOLOGY}

This is a qualitative study informed by grounded theory methodology as described by Charmaz. ${ }^{20}$ It involves interviews with parents of extremely preterm babies who were cared for in The Townsville Hospital (TTH) NICU, some years after their NICU experience.

\section{Context of setting of study and population}

North Queensland has a large geographical area of $500000 \mathrm{~km}^{2}$, with a population of approximately 700 $000 .{ }^{21}$ There are four main regional centres where $72 \%$ of the population resides, with the remainder living in smaller towns, in remote and very remote locations. Remoteness is defined by the Accessibility/Remoteness index of Australia produced by the Australian Bureau of Statistics, which defines areas by their distance from services including advanced medical care. The population is ethnically diverse including $12.3 \%$ Aboriginal peoples or Torres Strait Islanders (hereafter referred to as Indigenous) ${ }^{22}$ and has a diverse socioeconomic status. Tertiary-level maternal fetal and neonatal services are provided for the region at TTH, which provides care for babies of any gestation above 23 weeks and babies with most surgical conditions. Patients requiring cardiac or ophthalmic surgery travel to Brisbane, the capital of the state, which is $1337 \mathrm{~km}$ from Townsville. While admitted to TTH, all babies receive care from the on-call neonatologist and do not have an individually named specialist.

Where a pregnancy is likely to result in a baby requiring tertiary neonatal care, or below 28 weeks' gestation, attempts are made to ensure delivery at TTH. Babies who deliver outside of TTH who require intensive care are transferred to the TTH by a retrieval service staffed by the neonatal unit. There are more than 10000 deliveries per year in North Queensland. TTH admits 800 babies annually for neonatal care including 40-50 under 28 weeks' gestation. Thirty-eight per cent of extremely preterm babies at TTH are of Indigenous origin and 27\% are from remote or very remote areas. Twenty-five per cent of the extremely preterm babies are delivered outside of TTH and require retrieval. ${ }^{23}$ Once the babies are at an acuity that can be catered for closer to their home, they are transferred back to referring hospitals.

\section{Patient and public involvement}

The study is part of a bigger project that investigates parental involvement in decisions made to resuscitate extremely preterm babies. The project was initiated in response to a parent who felt she had been excluded from decisions made to offer intensive care to her preterm baby. The mother became a participant in this study and suggested some of the questions used to guide the interviews. Participants were asked if they wished to receive the results of the study, and these participants will be sent a copy of any papers resulting from the study.

\section{Ethics approval}

All participants gave informed consent to participate in the study.

\section{Sampling strategy}

Potential participants were identified from the TTH NICU database using the criteria of extreme prematurity or complex antenatal surgical diagnosis, families resident in the North Queensland area at the time of admission, fluent in English and delivered between 2010 and 2015. The first eight eligible families of babies born in 2012 - chosen as the approximate mid-point of the study-received a participant information sheet and consent form by post to initiate the recruitment. Parents were requested to contact the administration officer by telephone to arrange an interview at their convenience if they wished to participate. Three families were recruited from the mailout. Three participants were then snowball recruited from initial participants at the request of one of the original participants. Review of the characteristics of the then six participants, and the iterative coding of interviews, led to more purposive recruitment from the database thereafter to encompass the range of parental age, age of child, rurality of residence and ethnicity, as well as a subjective assessment of the difficulty of the neonatal stay and the impairment of the children as is appropriate for grounded theory research. These potential participants received the information sheet and consent form as per 
the original recruitment, as well as a follow-up call from administrative staff. There were 15 families approached in the purposive recruitment phase, of whom 11 participated before data saturation was achieved.

All potential participants were offered a choice of interviewer (the primary investigator who is a neonatologist or an alternative interviewer with a neonatal nursing and research background), but all participants chose the primary investigator. Indigenous participants were offered interviews by, or attended by, Indigenous liaison officers, but all declined this.

\section{Data collection}

The location of interviews was chosen by the participants, most choosing to be interviewed while at the hospital for other appointments. One interview was done by telephone, one arranged for a location at an alternative hospital and one interview at the patients' home. All interviews were digitally recorded. For half of the interviews, the child under discussion was present. All interviews included the mother, and for six interviews, both parents chose to be interviewed together.

Consistent with grounded theory principles, initial interviews followed a question guide, which was modified in response to iterative analysis as the interviews progressed. The interview explored experiences, decision making and participant opinions about potential improvements in the service. Interview length ranged from $20 \mathrm{~min}$ to $85 \mathrm{~min}$, with one interview of $45 \mathrm{~min}$ being done during a 4-hour visit to the family home. The home visit was requested by a parent who wanted the researcher to have a more complete understanding of the life lived with a severely handicapped child.

\section{Data analysis}

The research team met regularly and discussed interviews iteratively. Using NVivo as a data management software, interviews were analysed using open coding. Themes were identified from the codes using a staged constant comparative process from focused coding to theme generation. While the primary investigator did the initial coding, a triangular approach using collaboration with the study team was used to develop themes.

\section{RESULTS}

\section{Summary of participants and outcomes}

Seventeen families were interviewed, representing the diversity of developmental outcomes, the ethnic and socioeconomic variation and varied location of usual residence of the parents seen on the unit (table 1). Eleven mothers were interviewed alone, and six couples chose to be interviewed together.

Characteristics of the participants were recorded following chart review.

Five mothers had suffered a previous pregnancy loss, and four had undergone fertility treatment. Nine women had spontaneous preterm labour causing the delivery, six had preterm prolonged rupture of membranes, one had an antepartum haemorrhage from placenta previa and one was delivered preterm for maternal pre-eclampsia. Ten women were given adequate antenatal steroids, defined as two doses of betamethasone with the second given at least 24 hours prior to delivery. Several babies had complications of intensive care: two had an accidental drug overdose, one a liver laceration during surgery and one had an extravasation of parenteral nutrition into the liver from a misplaced central line. All survived. Three babies had an intraventricular haemorrhage grade three or four, or periventricular leucomalacia, four had necrotising enterocolitis requiring surgery and three required treatment for retinopathy of prematurity. Three babies died.

From parental report at the time of interview, of the surviving 19 children, 4 had severe disability, 4 had mild to moderate impairments and 11 had development in the typical range. One child required ongoing bowel and urological surgery for congenital anomalies. One child had a congenital renal abnormality. Parents considered severe disability to encompass mobility problems that required the child to be dependent on an aid or caregivers and/or intellectual impairment requiring a high level of support or special arrangements for schooling, mild to moderate impairment to include motor, learning and speech delays of a lesser degree that required therapy but no special aids or school assistance. The veracity of the parental reports was not examined.

Table 1 Participants and outcome demographic

\begin{tabular}{ll} 
Gestation & Median: 25 weeks; range: 24-30 weeks; IQR: 24-26 weeks. \\
Birth weight & Median: 867 g; range: 600-1770 g; IQR: 650-959 g. \\
Gender & Male 10 (45\%). \\
Survived to discharge home & $19 / 22(86 \%)$. \\
Time from delivery to study interview & Median: 3years; range: 2-7 years; IQR: 2-5years. \\
Place of residence of family & Local: 7 (37\%); out of Townsville region: 10 (63\%). \\
Maternal age at time of birth of baby & Median: 31 years; range: 18-37 years; IQR: 23-35. \\
Ethnicity of mother & Caucasian: 11, Indigenous: 3; Māori: 1; Asian: 2. \\
Pleurality & 12 singletons, five sets of twins. \\
\hline
\end{tabular}




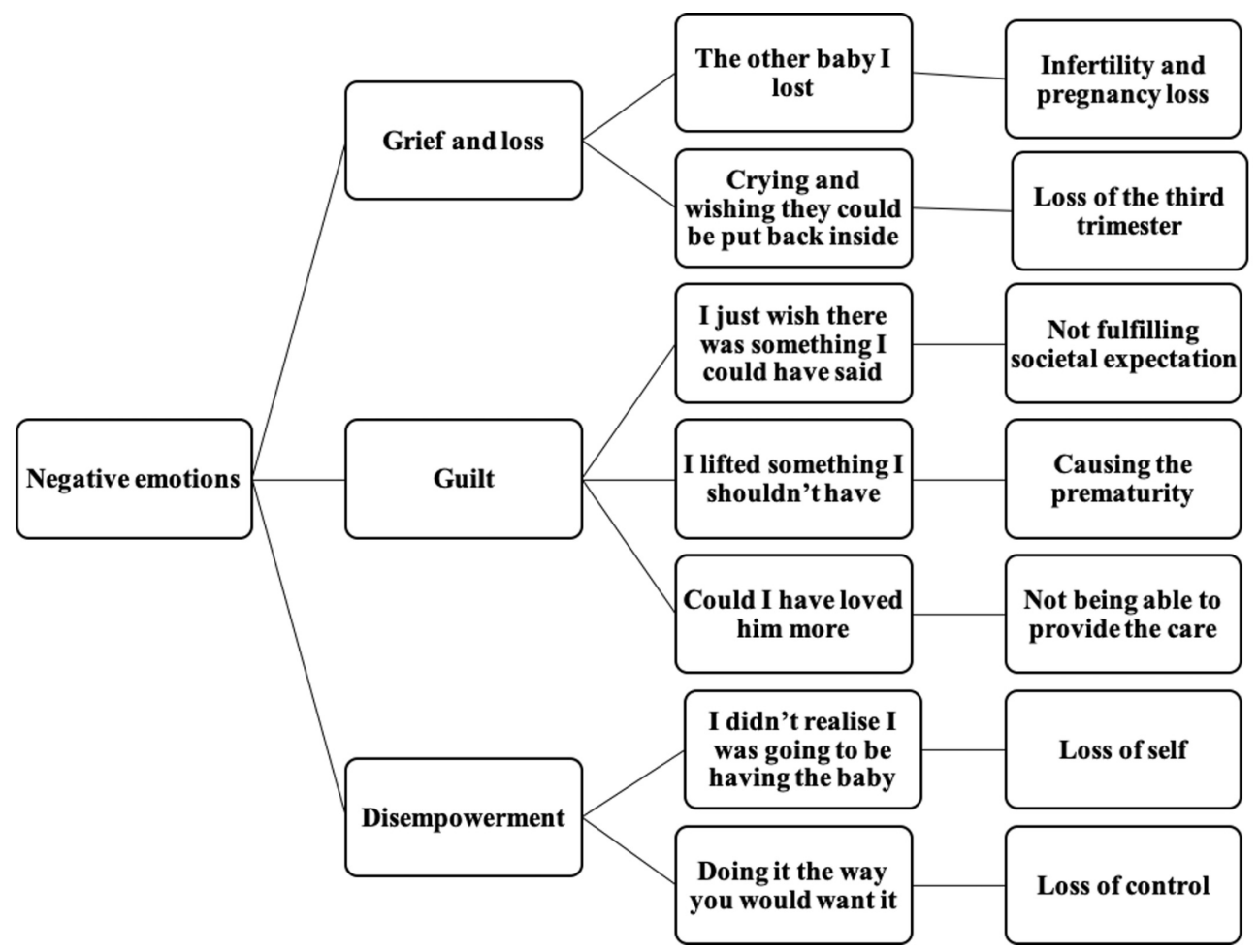

Figure 1 Negative emotions.

\section{Qualitative reflections}

Themes could be grouped into experiences of negative emotions and positive enhancers. Parents' descriptions of life on the neonatal unit include negative emotions of grief and loss, guilt and disempowerment (figure 1). The grief and loss is a summation of previous loss or fertility issues and the loss of the completed pregnancy. They wished that they had more knowledge about the potential for premature delivery and more assertiveness around the time of delivery to challenge medical decisions that were made. There is parental guilt at the failure to reflect societal expectations of healthy reproduction and parenthood. Themes expressing positive enhancers (figure 2) reflected the family strengths prior to the NICU experience, including intrinsic supports such as culture and religion, as well as new experiences engendered by good staff practice and external supports. For many families, the positive experiences that they had during their neonatal course helped them to cope, but for some, this did not seem to mitigate the failure and guilt which they described. Themes and subthemes are summarised in figures 1 and 2, then outlined in more detail with quotes in the following sections.

\section{Negative emotions}

Grief and loss

'The other baby I lost'

Parents commonly shared traumatic stories of prior pregnancy loss and fertility difficulties. These stories emerged unprompted when parents were asked to reflect on the birth of the study baby.
I lost a baby at 18 weeks 3 months before I conceived L. I thought, oh, here we go again... I just thought I will let nature take its course, and whatever happens, happens... Having had the experiences that I had before, I just said I'm not having any more babies anyway, so I really don't care. (Mother of a baby born at 25 weeks after membranes ruptured at 18 weeks)

After my first pregnancy, we aborted a pregnancy... That baby could have been a girl, because I wanted a girl, and that baby could have been healthy.... So I personally believe that I've done something wrong. (Mother of a 24-week-old baby with severe impairment)

\section{'Crying and wishing... they could be put back inside'}

Mothers particularly mourned the loss of a full third trimester of the pregnancy. The third trimester is a time for preparing for birth, both mentally and physically, with the expectation of a healthy delivery. Societal rituals to celebrate the pending birth such as baby showers occur. Loss at this part of the pregnancy is described by one mother as an horrific experience.

I was just in severe shock. I felt like I was being hacked open and my babies were being stolen from me. It was awful. They had to knock me out in theatre because I couldn't... I just lost it... I spent the first week-all I can remember is crying and wishing that he could be put back into me-both actually. That they could be put back inside. (Mother who went into preterm labour at 26 weeks following the death of one twin in utero) 


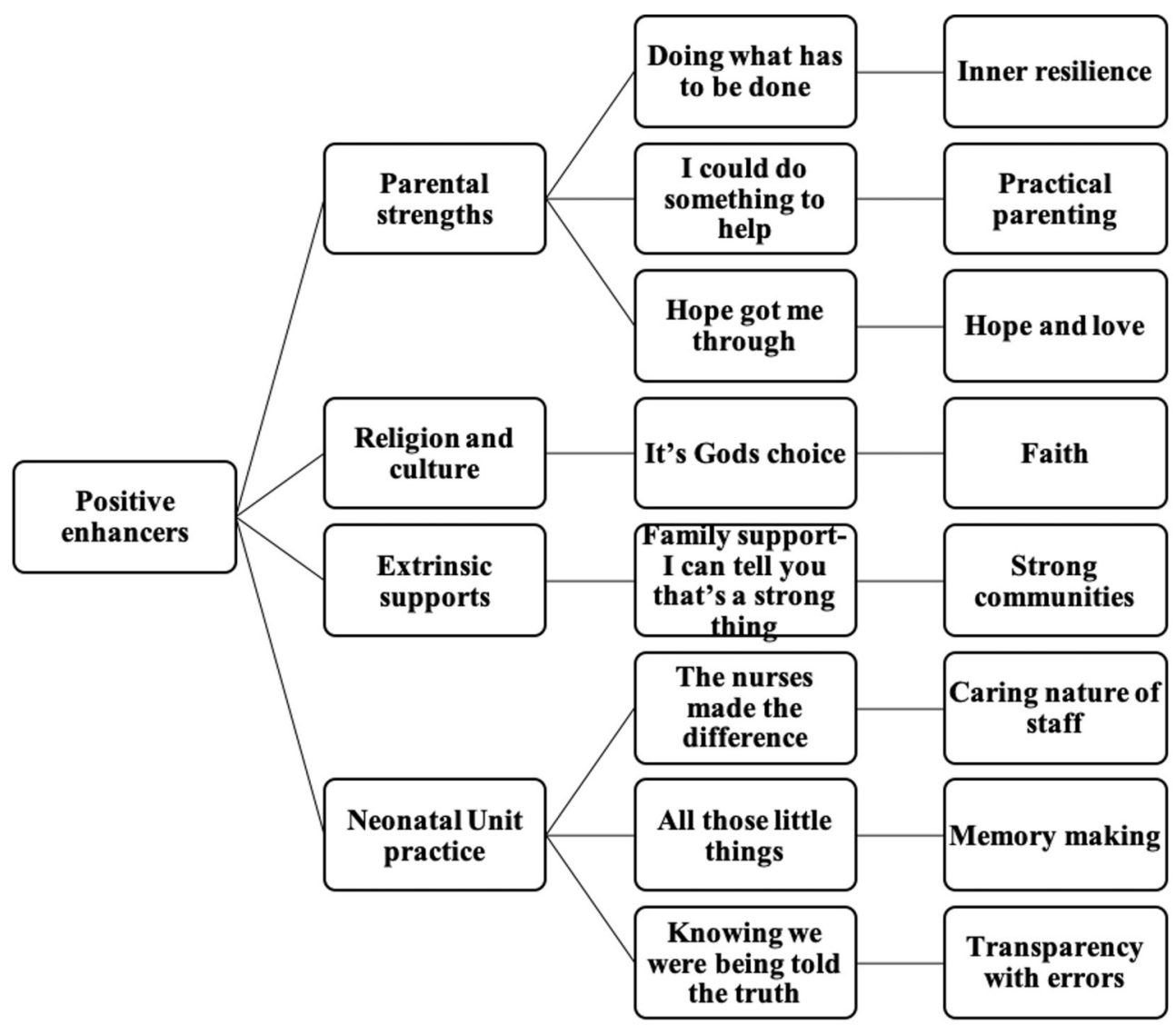

Figure 2 Positive enhancers.

The loss of a typical term baby was felt by a father who recognised that the baby did not look like a 'normal' baby, but the deviation from typical neonatal progress took a long time to accept.

He looked like a little plucked pigeon. Then I was like, okay, he's just-you know, not knowing because I didn't know. See, I thought it must be normal if that makes any sense. Then as we got into the apparatus and everything on him, I was like, 'yeh, right'. Then we got into more and more of it. It was just dawning on me. Right up until the end (when he died). (Father of a 24-week-old baby who died of complications of prematurity at 3 months of age)

\section{Guilt}

\section{'I just wish there was something I could have said'}

Societal expectations dictate that parents should protect themselves and their families. Many parents perceived that they had been failed by inadequate medical evaluations and decisions. The impotence of parents in the face of medical superiority resulted in feelings of guilt for not challenging these medical decisions antenatally as they felt that this may have altered the outcome.

Why was I bleeding all the time? This is ridiculous, they were like, 'oh, we see people bleed all the time. We see worse than this'. Then I'm like, shouldn't I be on bed rest or something or should I be hospitalized?
Other people I know are hospitalized. They were like, no, we don't hospitalize until 24 weeks....we see placenta praevia all the time. It moves. It goes. You'll be fine. Everyone just kept living on the glass half full theory. You'll be fine. No-one said, oh, you might hemorrhage and have the baby at 24 weeks and you might nearly die. Geez, if someone had actually told me what potentially could happen, I wouldn't have moved. I wouldn't have stepped off my couch. I would not have left my house. I would have taken so many steps. (Mother of 24-week-old child who is profoundly disabled)

Several mothers expressed that by delivering their babies early they had not been able to fulfil a natural function and thus had failed societal norms.

It's just ridiculous. We're here to procreate. That's our job. That's our body's job. (Mother of a 24-week gestation boy with multiple complications)

I was devastated and I couldn't believe that my body had failed them both. It was awful. I felt terrible, really, really bad.... I hated myself for failing him and I just wanted him back in there. So that was the first week, nightmare and I don't think I thought anything else except for that wanting them both back inside my stomach. (Mother of 26-week-old twins) 


\section{'I lifted something I shouldn't have'}

Parents discussed guilt at failing to protect the baby both prior and after delivery. Many of the mothers blamed themselves for causing the preterm delivery by actions that they thought may have resulted in early labour or rupture of membranes.

I lifted something I shouldn't have and my waters broke probably about an hour after that. (Mother of 26-week gestation baby, who has four older children)

Guilt was expressed by parents with complicated pregnancies and who had made decisions, which, in retrospect, they worry may have caused the extreme preterm delivery.

'if $\mathrm{M}$ (twin 1 with multiple abnormalities) makes it to being born, we (the doctor) will not intervene. So we will leave him there to die.' That's what they had said to that us in those words... But we always have to ask the question now don't we, that if we had just left him alone and hadn't done the foeticide, would B (twin 2) have made it to term. (Parent who delivered 26 week twin pregnancy following the fetocide at 23 weeks of the twin with multiple anomalies)

Parental guilt extended to decisions made with parental involvement after the birth of the baby. Often different potential treatment options occur in neonatal care, with no clarity about the best option. However, the outcomein this case death-led the father to feel guilty about having a role in decision making.

[T] hey talked about steroids stunting growth and that sort of jazz but looking back on it now I wish I just got out of your way a little bit... the advice I'd give a parent now is definitely don't not ask questions but display some trust. Whereas in the beginning I may have got in the way a little bit. That's just something I have to live with now. (Father of 24-week-old baby who died after 3 months with chronic lung disease)

\section{'Could I have loved him more?'}

Parents felt guilty about being unable to provide the full-time care that the baby required as the level of care for extremely preterm babies is specialised and done primarily by nursing staff. As a result, parents spend many hours sitting besides the cot without being able to handle the baby. The parents needed to continue life outside the unit, but also to escape the stresses of the NICU.

Like, did I spend enough time there? You know, should I have loved him more? Could I have loved him more? You know, all those sorts of things used to go through my head. (Mother of 25-week-old baby who had many complications and long term sequalae)

[A]nd I wouldn't go near it like for two days at a time, because I just couldn't even sit there and listen to the beeping anymore or the crashing. ... The whole thing just gave me anxiety, because I couldn't protect him. (Mother of severely disabled child)

The act of providing emotional care is also recognised by parents as an important aspect of care but still leads to guilt when provided by the nursing staff.

Even though I knew the nurses were amazing, I would ring up every time after I'd leave, before bed, five o'clock in the morning. I knew she was in good hands, but it was like, who's there patting her to sleep? Who's there cuddling her? Then when I would come in sometimes and see nurses had been there massaging her and having a cuddle with her, it was like, oh she's - because it's a month before you can take them, and they're in there by themselves every night. Yeah, so it did worry me. (Mother of 24-week-old girl)

\section{Disempowerment}

\section{'I didn't realize I was going to be having the baby'}

Loss of self and personal autonomy was expressed where some mothers presented in preterm labour and events happened very rapidly over which they had no control. Parents did not recall being aware of the imminence of birth or an opportunity to make resuscitation decisions.

I do remember that I didn't really realise that I was going to be having the baby, until they induced me and I delivered her. Because it wasn't explained very well that I was at high risk of having her. (Mother of 26-week-old baby admitted for medical complications of pregnancy)

False reassurance removes the opportunity for parents to be prepared for the delivery.

'That will stop the contractions, everything will be fine'. Then as soon as I had the examination, it was lights, camera, action. Oh shit, it's happening. Everyone was pretty highly stressed, I don't remember any options being given to me... They were very reassuring with everything they were doing, but I don't remember many options. (Mother who delivered at 24 weeks, who had previously had 24-week-old twins)

\section{'Do it the way you would want it'}

Parents describe how having the baby's care provided by others left them disempowered.

$[\mathrm{Y}]$ ou wouldn't really feel like it's your baby, because the nurses are doing everything. You're kind of just doing nothing when you know you're their parents and you're meant to be doing everything for them.... some days you come in, sometimes the nurses will have done everything and you're just kind of like, feel a bit - yeah. (Parents of 27-week-old twins)

Some had concerns where they felt that some staff members did not provide a quality of care which they as parents would like to observe. 
All of that horrible, horrible time when you're forced in this situation to leave your child in the care of people that you would not choose to leave your child with. Some of the nurses, oh my God... there's no way you would let them look after your child in the real world, if you had a say. (Parent of 26-week-old surviving twin)

Errors in care also caused anger in this mother who felt unable to prevent harm from occurring.

I would put it down to the worst day of my life. (drug overdose)... that she would die through something that could have been prevented. (Mother who delivered after 7 weeks of ruptured membranes)

\section{Facilitators of resilience: positive enhancers}

In contrast, a range of factors led to positive experiences on the neonatal unit. Resilience of parents was a result of both intrinsic factors that were inherent in the parents' own abilities to cope, as well as external factors within the community of staff, and the parents' wider social communities.

\section{Parental strength}

\section{'Doing what has to be done'}

Parents reflecting all strata of society find themselves in a complex and stressful situation when their baby was admitted to the neonatal unit. An inner resilience described by many parents helped them cope well with the difficulties of the neonatal unit as well as complex medical pathways required for their children after discharge.

People say to me the whole time-'you are such a strong person', and I say 'no that's not true, I just do what has to be done', so for me if it has to be done it gets done, you know, like appointments and everything else. (Mother of a 25-week-old boy who had a long and difficult neonatal admission and who has complex medical needs)

Some mothers reflected that they had themselves had difficulties in their upbringing that made them more resilient.

I guess I knew it wasn't indefinite coming here every day. I'm a pretty resilient person. I just had to stick it out... I guess I've had a pretty hard life. (Mother who birthed a 25-week gestation baby after educating herself extensively about prematurity)

Inner resilience can be a function of one parent—often the mother, as mothers are usually the main caregivers on the neonatal unit, but also of the parental dyad.

The good thing is we stayed solid through the whole thing. There was never a moment of resentment towards each other. We were solid through the whole thing which is [pretty hard] - I think it brought us closer. (Parents of 24-week gestation boy)

\section{'I could do something to help'}

Most mothers learnt how to look after their baby in ways which would be different to that required for a healthy term baby. Real pride in being able to do practical aspects of care that were useful to the baby were clearly articulated.

... when you actually get to pump out your own milk, and it's working and there is actually real milk in there, that's a real achievement. (Young mother, first baby of 25-week gestation, very proactive in decision making)

So I was so glad that I could do something to help because that was really the only thing I did that helped him (bringing in cucumber for his sore eyes following an eye screening examination). (Mother of surviving twin)

Having a constant presence on the ward and advocacy for their baby was recognised as resulting in a positive outcome.

I'm not a spiritual person and I don't believe in all that kind of thing but I sit here today and I think the reason why my kids are here is because I was positive, because I was there and because I was fighting for them the whole time I was in here. I honestly do believe that's why they're here and why they're so healthy, because I was their voice. I was there for them. The only advice I can give is to be positive. (Mother of 24-week-old twins who had an uncomplicated neonatal course)

\section{'Hope got me through'}

Hope, love and a belief that their child would survive regardless of the known mortality rate and severity of illness of the baby was described as important and leading to the survival of the baby.

The hope that I had is what got me through and I think what got them through. That's all I could focus on at the time. I just blocked it out. I just didn't want to know that there was anything wrong with them... You've just got to be 100 per cent positive the whole time you're in here to get through it and you've got to be the strong person. (Mother of twins, one of whom had a significant brain bleed)

I just knew deep down that everything was going to be okay, and that's fine... That's probably the first highlight for me, was the fact that she was responding... So it was hour by hour... that was my positive that came out of that, that she was still alive.... I thought she'd always survive. (Mother who was quoted less than $1 \%$ chance of survival for the baby at antenatal counselling)

\section{Resilience through religion and culture}

'It's God's choice'

Religious beliefs also helped parents with remaining positive. While few parents described themselves as religious, 
parents who did have an active faith or spirituality found that they could turn to their faith, believing that their faith was strengthened and this helped their child to survive.

... like a little inner voice that used to say he'll be okay. Just keep that hope. Keep that faith that he's going to be okay. I used to go to the church all the time here and pray and things like that. (Mother of 25-week gestation boy with multiple complications of prematurity. Redirection of care to palliatiation was discussed but declined by the parents)

For parents who described themselves as not religious, improvement in the condition of their babies was ascribed to a religious incident. Belief in a 'higher power' was common.

At work there were Mormons. When the girls were going through a really bad time with the brain bleeds, they had asked if we could have some Mormons come here coming in and just say a prayer and I guess, do the little things that they did. So we did have that and it's not that I don't believe-I mean there's just so much different things. But a few days later they started getting better and everything. We're not religious but I guess we're open to everything, we're just open to everything really. (Parents of 27-week-old twins, one of whom had a significant brain haemorrhage)

Cultural beliefs were equally important for some participants. Cultural beliefs lead both this Māori family, and one of the Indigenous mothers, to believe that the babies should be given every chance of survival.

D's Maori. Cultural, very cultural-he's very-with his culture. believing that all babies should be given a chance of resuscitation. (Mother of 24-week0old girl, who previously had 24-week-old twins)

\section{Extrinsic supports}

\section{'Family support-I can tell you that's a strong thing'}

Parents described supports extrinsic to themselves, such as family support, community support and other parents on the unit. Strong family support helped many parents to thrive in the neonatal unit.

So it was a big family support. I can tell you that it was a strong thing. Even in the community where-the few Indians..., the community-because they were the only people I knew. (Mother of 24-week-old twins, one of whom survived)

Other supports came from parents who were in a similar situation on the neonatal unit and resident in the on-site accommodation was important.

... [W] hen you saw the parents and you talk aboutyou got to share war stories and things. That was good. (Parents usually resident $800 \mathrm{~km}$ from TTH)

The on-site accommodation, Ronald McDonald House was appreciated by the parents who resided long distances from the unit.
I don't even think I realised that Ronald McDonald was even there and I don't know-it just hadn't even crossed my mind of where are we going to be staying and what's the length of time we're going to be here for. So I think the social worker definitely helped a lot. I mean I guess even the staff at the neonatal unit ... even like just emotionally support. (25-week gestation baby who had several admissions to the neonatal unit for bowel surgery)

\section{Positive experiences engendered by neonatal unit practice}

In this study, the babies remained in hospital between 3 months and 8 months. Parents recognised that the staff did not merely perform a clinical function, and where staff paid attention to things outside of immediate clinical care, parents reflected on this positively. Parents also valued memory making and honesty.

\section{'The nurses made a difference because they are so happy'}

Parents appreciated non-clinical aspects of the nurses' activities.

... [W]e had quite a lot of good days and everything. I think the nurses and everything made a difference, because they're so happy and just someone would take-just little things like, I guess, one nurse always matched all the bedding, all their outfits. (Mother of 24-week-old twins)

... [O]nce you got to know them (nurses) you share a joke, it kind of became your second home. That was just very supportive. (Father of baby who stayed on the unit for 8 months)

During the time period that many of the participants were admitted, the unit participated in a programme called 'FiCARE', which enabled participation of the parents in nursing activities. Parents presented the baby on the medical ward rounds and were invited to make suggestions and ask questions.

Love it, love that program. It was so wonderful to feel like you could be involved in your child's care which is exactly how you should feel as a parent when your child is being looked after in a hospital. (Mother of 26-week-old surviving twin)

\section{'All those little things'}

Positive celebrations of the babys' progress through memory cards commemorating milestones such as achieving a weight of $1 \mathrm{~kg}$, or having a kangaroo cuddle were meaningful to parents.

Just lots of small things. Coming in on special occasions, Mother's Day, having a card made and stuff like that. When she-they go to a big bed or they get to a kilogram. All those little things. They're small, but they're high moments. (Mother of 24-week-old girl) 


\section{'Knowing we were being told the truth'}

Disclosure of inadvertent errors were a positive occurrence for some parents such as this mother:

I mean even the time with the drugs, when he went into the coma..., so I remember when X told us what had happened, P started getting angry, and I stopped him, and I said 'you know, these people are telling us the truth, and that's what I want' so I guess in a way, that's a high, knowing that we were being told the truth. (A 25-week-old baby who received an accidental overdose)

\section{DISCUSSION}

This study shows that parents have clear memories of positive enhancers and negative emotions of their neonatal unit experiences some years after their NICU admission. Negative themes of grief and loss, guilt and disempowerment were identified. It is known that negative emotions increase rates of parental anxiety and depression that in turn leads to negative effects on the development of the baby. ${ }^{5}$ Positive enhancers of their neonatal stay were parental strengths, religion and culture, family support and neonatal unit practices. Resilient parents with strong supports and positive experiences have shown improved family function and neurodevelopment of the child in early childhood. ${ }^{24}$

When parents in this study reflected on their neonatal experience, grief expressed for prior infertility and pregnancy losses was an unexpected finding not clearly seen in the literature studied. This suggests that with the perspective of time, parents locate their neonatal experience within a longer life experience of pregnancies that have not followed the typical pattern. Nine of the mothers interviewed had previous difficulties with pregnancy and all spontaneously discussed these. Previous preterm delivery, infertility and assisted conception are risk factors for subsequent extreme prematurity. ${ }^{25}$ Resilience in some of these high-risk women was enhanced by their greater knowledge of prematurity and often stronger family support because of the previous problems. Empowerment through education about prematurity and NICU, as well as a focus on social support at the high-risk obstetric clinics where these women are seen may enhance resilience should the women then delivery early.

This study found parents felt guilty about failing to perform within societies expectations by delivering before term, and lacking the skills to look after their preterm baby. In the Etude Epidemiologique sur les Petits Ages Gestationnels (EPIPAGE) study where parents were interviewed during or shortly after neonatal experiences ${ }^{26}$ guilty feelings were noted to negatively impact on the feelings towards the child and increase parental feelings of physical exhaustion. We did not find this, which may reflect the time frame at which we interviewed the parents. This suggests that although parents still felt guilty, the negative effects of the guilty feelings faded as the fatigue associated with early infancy ceased.
Disempowerment through loss of control over their situation and the care for their babies was universal. This is similar to other studies where disempowerment is described as powerlessness. ${ }^{9} 19$ Models of care such as the FiCare programme aim to empower parents through sharing the care of the baby with staff, improves neonatal outcomes and leads to a better understanding by staff about the difficulties that parents face. ${ }^{27}$ In this study, parents who perceived the highest levels of disempowerment appeared to have the most difficulty with their acceptance of their childrens' disabilities. They described more negative emotions, with fewer positive enhancers in their reflections of NICU care than parents of children with similar level of disability.

Parental resilience has been well described in the literature as an enhancer to coping on the neonatal unit. ${ }^{28} 29$ Additionally, studies show that the increased involvement of parents enables them to feel more connected to their baby, ${ }^{41530}$ and particularly expressed breast milk is seen as something the mother can provide that the nursing staff cannot. ${ }^{17}$ Parents talked about love for the child and hope for survival as enabling positivity. The personal experience of Janvier ${ }^{18}$ and others who had NICU babies reinforces this finding that hope was the most important positive feature of their experience and enabled them to cope with their difficult situation. Staff can play an active role in enhancing hope and positivity in parents.

Surprisingly, little is found in the literature about religious supports. A Turkish study provided 'active spiritual care' in a randomised trial on a neonatal unit ${ }^{31}$ and found that there was significantly less stress in mothers who received increased religious observance. While Turkey may be more religious as a country than Australia, our study suggests that even in relatively secular societies, religion, or a spirituality, is a positive enhancer in times of difficulty. Parents in our study who described themselves as religious, even if not devout, increased their own religious observation during this time, and others welcomed people of other religions to visit and pray for their baby as this seemed to enhance their hopes for their baby's survival and well-being. This finding has not been described in the literature.

Strong unit practices that support parents in their NICU stay are recognised in other studies. This included good communication, ${ }^{513} 15$ showing affection for the baby, ${ }^{13}$ being approachable and friendly, ${ }^{15} 3233$ providing parents with adequate information and celebrating milestones. We found that where nurses were noted to be caring, they provided parents reassurance that the baby would be comforted and competently cared for. Parents were helped to recognise that their baby was progressing by the provision of mementos in memory making rituals.

Trust in staff was engendered by dealing with mistakes in a transparent manner. While honesty is known to be valued by NICU parents, ${ }^{18} 19$ this is usually in the context of discussing the baby's well-being, prognosis and management. Honesty in transparency and admitting errors to parents has not been described in studies 
of NICU experiences. In this study, it was spontaneously discussed by three families.

All parents, even those who had more negative experiences and those with children with severe handicaps, described good attachment. This is unlike studies that were done closer to the neonatal stay. ${ }^{71011}$ This is an important finding. In the same way that some parents have incorporated their previous history of infertility and pregnancy loss, the neonatal course appears to have become part of the family history. With the perspective of time, the parents became more philosophical about any impairment and described these as an expected cost of prematurity. The family has moved on to function and progress, with healthy attachment, advocating for their children's needs to overcome residual challenges. Reassuring parents that feelings of ambivalence towards the baby will improve may be possible with appropriate support. Healthcare staff may recognise the difficulty that families have with a sick neonate but not realise that families can thrive in time despite long-term sequelae. Reassuring staff that families do thrive may better inform them when counselling families.

The study aimed to include Indigenous families as this group of patients have not previously been included in similar studies. While it is desirable for research in Indigenous families to be conducted by Indigenous researchers, all families declined Indigenous support for interviews. We found that Indigenous cultural beliefs gave families a conviction that their child would survive. However, we did not find any other differences between Indigenous and non-Indigenous families in terms of experiences on the neonatal unit. The Indigenous families recruited reside in urban areas and were of varying socioeconomic status. Most of the Indigenous population of North Queensland resides in urban areas. The findings were verified by discussions with the Indigenous colleague as likely to be representative of urban-dwelling Indigenous Australians but may not represent families from remote settings. Further research into the experiences of Indigenous families is essential to fully inform and improve the provision of services for this group.

\section{Strengths and limitations}

A strength of this study is that it managed to document a range of experiences that largely represented the population of the unit, including Indigenous families, who have often been omitted from Australian studies. The study has been done when the admitted baby is older, and the parents have had time to reflect for longer on their experiences and recover from the experience to some extent. Many had made significant life changes as a result of this reflection. Another strength is that the primary researcher knew all of the families and had cared for the babies as a neonatologist. This may have enabled the parents to be frank in their interviews, although concerns could be raised that this might have limited some parents from expressing their views. However, all parents had all chosen to be interviewed by the primary researcher and share negative experiences, indicating that views were not suppressed. Additionally, a good range of regionality of parents was possible due to the opportunistic interviewing of some families during visits for other medical appointments. The primary researcher used reflexivity to consider the potential to bring her personal views and professional lens on the study and influence initial analysis. Reflexive discussion with the research team and collaborative analysis improved credibility and confirmability of results.

A limitation of the study may be that the Aboriginal and Torres Strait Islander representation may be inadequate, as the participants from these groups from very remote areas did not engage in the study. This may be a cultural difference as the families may not have been aware of qualitative research as a scientific method. The families may have felt uncomfortable being interviewed. Recruitment may have been improved by the use of more culturally appropriate workers at the initial recruitment phase. More research involving Indigenous parents from remote communities needs to be done to ensure that this under-represented group has an adequate voice in their experiences in this field.

Parents who felt negatively about the unit, either because they had a bad experience or a poor outcome may not have engaged with the study. A further limitation could be that this is a study from a single regional NICU and the transferability and generalisability of the findings may be limited.

\section{CONCLUSION}

Parents who have extremely preterm babies describe an intense range of experiences, both positive and negative from their NICU stay. New findings in this study are the parents' ability to contextualise their NICU experience within their wider life experience, suggesting that they can encompass it as something in the past from which they have moved on. Good attachment occurs as families cope with any long-term impairment of the child. Our research adds to the evidence that should help neonatal units to enhance parental experiences. Improved experience will lead to improved long-term outcomes.

Acknowledgements The authors would like to thank the mother who encouraged the study in its entirety by raising her concerns to the primary author. The authors would like to thank all the parents who participated in the study and the staff on the neonatal unit who facilitated appointments. Narelle Draper, indigenous liaison officer and colleague assisted with indigenous-specific aspects of the study.

\section{Collaborators Narelle Draper.}

Contributors All authors designed the study; SI performed the interviews; RAR, SL and LW contributed to the analysis and writing of the paper.

Funding This work was supported by a Study, Education and Research Trust Account (SERTA) research grant awarded by the Townsville Hospital and Health Service grant number 62606.

Competing interests None declared.

Patient consent for publication Not required. 
Ethics approval Approval for the study was received from the Townsville Hospital Health Service Human Research Ethics Committee (HREC/15/QTHS/195), and from James Cook University Ethics Committee (6484).

Provenance and peer review Not commissioned; externally peer reviewed. Data sharing statement Data for this study are available from the primary author. Open access This is an open access article distributed in accordance with the Creative Commons Attribution Non Commercial (CC BY-NC 4.0) license, which permits others to distribute, remix, adapt, build upon this work non-commercially, and license their derivative works on different terms, provided the original work is properly cited, appropriate credit is given, any changes made indicated, and the use is non-commercial. See: http://creativecommons.org/licenses/by-nc/4.0/.

\section{REFERENCES}

1. Seaton SE, Barker L, Draper ES, et al. Estimating neonatal length of stay for babies born very preterm. Arch Dis Child Fetal Neonatal Ed 2019;104:fetalneonatal-2017-314405.

2. Wilkinson AR, Ahluwalia J, Cole A, et al. Management of babies born extremely preterm at less than 26 weeks of gestation: a framework for clinical practice at the time of birth. Arch Dis Child Fetal Neonatal Ed 2009;94:2-5.

3. Lupton D, Fenwick J. 'They've forgotten that I'm the mum': constructing and practicing motherhood in special care nurseries. Social science \& medicine 1982;2001:53.

4. Wakely L, Rae K, Keatinge D. Fragile forgotten families: parenting a premature infant in a rural area, where is the evidence? Neonatal, Paediatric \& Child Health Nursing 2015;18:8.

5. Woodward LJ, Bora S, Clark CA, et al. Very preterm birth: maternal experiences of the neonatal intensive care environment. $J$ Perinatol 2014;34:555

6. Busse M, Stromgren K, Thorngate L, et al. Parents' responses to stress in the neonatal intensive care unit. Crit Care Nurse 2013;33:52-9.

7. Jackson K, Ternestedt BM, Schollin J. From alienation to familiarity: experiences of mothers and fathers of preterm infants. $J$ Adv Nurs 2003;43:120-9.

8. Gibbs D, Boshoff K, Stanley M. Becoming the parent of a preterm infant: A meta-ethnographic synthesis. British Journal of Occupational Therapy 2015;78:475-87.

9. Watson G. Parental liminality: a way of understanding the early experiences of parents who have a very preterm infant. $J$ Clin Nurs 2011;20:1462-71.

10. Medina IMF, Granero-Molina J, Fernández-Sola C, et al. Bonding in neonatal intensive care units: Experiences of extremely preterm infants' mothers. Women and Birth 2017.

11. Spinelli M, Frigerio A, Montali L, et al. 'I still have difficulties feeling like a mother': The transition to motherhood of preterm infants mothers. Psychol Health 2016;31:184-204.

12. Widding U, Farooqi A. "I thought he was ugly": Mothers of extremely premature children narrate their experiences as troubled subjects. Feminism \& Psychology 2016;26:153-69.

13. Smith VC, SteelFisher GK, Salhi C, et al. Coping With the Neonatal Intensive Care Unit Experience: Parents' Strategies and Views of Staff Support. The Journal of Perinatal \& Neonatal Nursing 2012;26:343-52.
14. Turner M, Chur-Hansen A, Winefield H. Mothers' experiences of the NICU and a NICU support group programme. Journal of Reproductive and Infant Psychology 2015;33:165-79.

15. Russell G, Sawyer A, Rabe H, et al. Parents' views on care of their very premature babies in neonatal intensive care units: a qualitative study. BMC Pediatr 2014;14:230.

16. Abdel-Latif ME, Boswell D, Broom M, et al. Parental presence on neonatal intensive care unit clinical bedside rounds: randomised trial and focus group discussion. Arch Dis Child Fetal Neonatal Ed $2015 ; 100$.

17. Rossman B, Greene MM, Meier PP. The role of peer support in the development of maternal identity for "NICU Moms". JOGNN - Journal of Obstetric, Gynecologic, \& Neonatal Nursing 2015;44:3-16.

18. Janvier A, Lantos J, Aschner J, et al. Stronger and More Vulnerable: A Balanced View of the Impacts of the NICU Experience on Parents. Pediatrics 2016;138.

19. Cohn F. Suddenly "I" Was a "Them". Current Problems in Pediatric and Adolescent Health Care 2011;41:111-2.

20. Charmaz K. Constructing grounded theory. 2nd edn. London: SAGE Publications Ltd, 2014.

21. Office QGS. qld-regional-profiles. 2017 http://www.qgso.qld.gov.au/ qld-regional-profiles.accessed

22. Queensland regional profiles: indigenous profile for catchment region [Internet]. 2016 http://statistics.qgso.qld.gov.au/profiles/qrp/ indigenous (Accessed 01 June 2018).

23. Ireland S, Larkins S, Ray R, et al. Adequacy of antenatal steroids, rather than place of birth, determines survival to discharge in extreme prematurity in North Queensland. J Paediatr Child Health 2019;55:205-12.

24. Treyvaud K. Parent and family outcomes following very preterm or very low birth weight birth: a review. Semin Fetal Neonatal Med 2014;19:131-5.

25. Frey HA, Klebanoff MA, eds. The epidemiology, etiology, and costs of preterm birth. seminars in fetal and neonatal medicine: Elsevier, 2016.

26. Garel M, Dardennes M, Blondel B. Mothers' psychological distress 1 year after very preterm childbirth. Results of the EPIPAGE qualitative study. Child Care Health Dev 2007;33:137-43.

27. O'Brien K, Bracht M, Robson K, et al. Evaluation of the Family Integrated Care model of neonatal intensive care: a cluster randomized controlled trial in Canada and Australia. BMC Pediatr 2015; $15: 210$

28. Janvier A, Barrington K, Farlow B. Communication with parents concerning withholding or withdrawing of life-sustaining interventions in neonatology. Semin Perinatol 2014;38:38-46.

29. Smith VC, Steelfisher GK, Salhi C, et al. Coping with the neonatal intensive care unit experience: parents' strategies and views of staff support. J Perinat Neonatal Nurs 2012;26:343-52.

30. Cleveland LM. Parenting in the Neonatal Intensive Care Unit. Journal of Obstetric, Gynecologic \& Neonatal Nursing 2008;37:666-91.

31. Küçük Alemdar D, Kardaș Özdemir F, Güdücü Tüfekci F. The effect of spiritual care on stress levels of mothers in NICU. West J Nurs Res 2018;40:997-1011.

32. Turner M, Winefield $\mathrm{H}$, Chur-Hansen $\mathrm{A}$. The emotional experiences and supports for parents with babies in a neonatal nursery. Adv Neonat Care 2013;13:438-46.

33. Pepper D, Rempel G, Austin W, et al. More than information: a qualitative study of parents' perspectives on neonatal intensive care at the extremes of prematurity. Adv Neonat Care 2012;12:303-9. 